\title{
Reviewer Acknowledgements
}

Studies in Media and Communication (SMC) would like to acknowledge the following reviewers for their assistance with peer review of manuscripts for this issue. Many authors, regardless of whether SMC publishes their work, appreciate the helpful feedback provided by the reviewers. Their comments and suggestions were of great help to the authors in improving the quality of their papers. Each of the reviewers listed below returned at least one review for this issue.

\section{Reviewers for Volume 7, Number 2}

Andreas Veglis, Aristotle University of Thessaloniki, Greece

Antonio García Gómez, University of Alcalá de Henares, Spain

Aslı Sezgin, Osmaniye Korkut Ata University, Turkey

Begoña Montero-Fleta, Universitat Poltècnica de València, Spain

Bernard Naledzani Rasila, University of Venda, South Africa

Carmen Pérez-Sabater, Universitat Politècnica de València, Spain

Diego Santos Vieira de Jesus, International Relations, Brazil

Imed Ben Labidi, Doha Institute for Graduate Studies, USA

Javier Serrano Puche, University of Navarra, Spain

Jenny-Ann Danell, Umea University, Sweden

Joerg Tropp, Pforzheim University, Germany

Kunle Olufemi Aramide, The Polytechnic Ibadan, Nigeria

Millaray Salas, Pontificia Universidad Católica De Valparaíso, Chile

Nuran E. Isik, Izmir University of Economics, Turkey

Philemon Bantimaroudis, University of Cyprus, Cyprus

Refat Aljumily, Newcastle University, UK

Shiza Nisar, Lahore School of Economics, Pakistan

Simone Tosoni, Catholic University of Milan, Italy

William Thomas Howe, University of Oklahoma, USA

Young Joon Lim, University of Texas Rio Grande Valley, USA

Yuan Gao, Curtin University, Australia

\section{Patricia Johnson}

Editorial Assistant

On behalf of,

The Editorial Board of Studies in Media and Communication

Redfame Publishing

9450 SW Gemini Dr. \#99416

Beaverton, OR 97008, USA

URL: http://smc.redfame.com 